\title{
UPAYA DALAM MEMPERTAHANKAN ERGONOMIK DAN \\ PENCEGAHAN HAZARD PSIKOSOSIAL DALAM BEKERJA DEMI \\ TERCIPTANYA KENYAMANAN
}

Inayah Husna Sibarani / inayahhusna08@gmail.com

\section{LATAR BELAKANG}

Setiap tempat kerja selalu mempunyai risiko terjadinya kecelakaan. Besar kecilnya risiko yang terjadi tergantung dari jenis industri, teknologi serta upaya pengendalian risiko yang dilakukan. Kecelakaan akibat kerja adalah kecelakaan berhubung kerja pada perusahaan. Hubungan kerja ini dapat diartikan kecelakaan terjadi dikarenakan pekerjaan atau pada waktu melaksanakan pekerjaan. Secara umum kecelakaan disebabkan oleh tindakan perbuatan manusia yang tidak memenuhi keselamatan (unsafe human action) dan keadaan lingkungan yang tidak aman (unsafe condition) (Suma'mur, 2014).

Salah satu sistem manajemen K3 yang berlaku seacara global atau internasional adalah OHSAS 18001; 2007. Menurut OHSAS 18001, manajemen K3 adalah upaya terpadu untuk mengelola risiko yang ada dalam aktivitas perusahaan yang dapat mengakibatkan cidera pada manusia, kerusakan atau gangguan terhadap perusahaan. Manajemen risiko terbagi atas tiga bagian yaitu Hazzard Identification, Risk Assesment and Risk Control (HIRARC). Metode ini merupakan bagian dari manajemen risiko dan yang menentukan arah penerapan $\mathrm{K} 3$ dalam perusahaan (Ramli, 2010).

Semua orang akan bekerja lebih baik apabila berada di lingkungan yang sesuai dengan pekerjaanya dan juga peralatannya (Mills, 1991). Setiap individu dalam suatu organisasi pasti akan berinteraksi dengan segala sesuatu yang bersifat fisik disekitarnya seperti bangunan, peralatan, dan barang-barang lainnya untuk dimanfaatkan atau didayagunakan (Sule, 2005).

Kondisi kerja yang telah berubah, dampak pada faktor risiko psikososial telah meningkat maka kinerja karyawan akan semakin rendah. Psikologis tuntutan pekerjaan adalah salah satu risiko psikososial utama dalam pekerjaan dan mengacu pada aspek pekerjaan yang akan membutuhkan usaha mental atau emosional. Meskipun tidak selalu negatif, tuntutan pekerjaan psikologis dapat memicu reaksi ketegangan dan stres ketika 
mereka membutuhkan terlalu banyak usaha. Jika berkelanjutan, psikologis tuntutan pekerjaan dapat mengakibatkan sakit (Niedhammer, Chastang, SultanTaieb, Vermeylen, \& Parent-Thirion, 2012).

\section{METODE}

Kajian ini menggunakan metode kualitatif, metode ini bersifat memberikan penjelasan dengan membuat analisis. Proses pengkajian ini lebih menggunakan landasan teori dengan mengumpulkan data, bereksplorasi bebas yang telah disimpulkan dari berbagai sumber-sumber, yaitu buku, majalah, koran, jurnal print maupun jurnal online bertema perencanaan keperawatan. Saya membaca dari berbagai referensi berupa buku, jurnal print maupun jurnal online. Melalui metode ini kita dapat memahami upaya dalam mempertahankan ergonomic saat keadaan bekerja dan mengetahui upaya dalam pencegahan hazard psikososial dalam lingkungan pekerjaan. Sehingga terciptanya keamanan dan kenyamanan dalam lingkungan pekerjaan saat waktu bekerja bagi para perawat di rumah sakit.

\section{HASIL}

Berdasarkan hasil yang saya dapat dari membaca berbagai sumber, bahaya psikososial dapat menyebabkan stres pada pekerja, hal ini dapat disebabkan oleh akumulasi stressor pada situasi kerja di tempat kerja. Misalnya, tuntutan pekerjaan dapat memicu timbulnya stres di tempat kerja. Menurut Randall R. Ross (1994), disebutkan bahwa stres kerja terjadi akibat adanya interaksi antara kondisi kerja dengan karakteristik pekerja dimana tuntutan pekerjaan melebihi kemampuan para pekerja. Hasil penelitian yang dilakukan oleh Wayne L. Chappelle (2014) menyebutkan bahwa stres kerja disebabkan karena upah rendah, tugas-tugas tambahan, sistem shift kerja, dan jam kerja yang panjang.

Bachkirova (2012) meneliti bahwa peran organisasi sangat penting dalam upaya mengurangi tingkat stres pada kerja. Organisasi/perusahaan harus mengetahui faktor-faktor yang memicu stres di tempat kerja agar dapat dilakukan pengendalian. Stres akibat kerja telah menjadi isu yang sangat penting. Stres sebagai suatu kondisi yang disebabkan oleh transaksi antara individu dengan lingkungan yang menimbulkan persepsi jarak antara tuntutan-tuntutan yang berasal dari situasi dengan sumber-sumber daya sistem biologis, psikologis dan sosial dari seseorang (Sarafino dalam Bart Smet, 1994).

Ergonomi menjadi pilar kesehatan dan menjadi salah satu indikator kesejahteraan. Menurut Meily (2013), perbaikan ergonomic perlu dilakukan 
sebagai salah satu upaya pencegahan terhadap penyakit CTDs (Cumulative Trauma Disorders) akibat faktor risiko kerja postur janggal, beban, frekuensi dan durasi yang bersumber dari pekerjaan, seperti nyeri tengkuk, nyeri pinggang bawah atau low back pain, rasa baal pada jari telunjuk, jari tengah dan jari manis yang disertai nyeri terbakar pada malam hari, kekakuan, lemah dan nyeri saat tangan digunakan dan dikenal dengan nama Carpal Tunnel Syndrome.

Dalam ergonomi, postur tubuh adalah faktor yang sangat penting, salah satunya postur duduk yang setiap orang lakukan setiap hari dalam durasi berjamjam. Tujuan utama membuat desain ergonomi untuk kursi atau tempat duduk dan meja adalah menciptakan sedemikian rupa bentuk kursi dan meja belajar, sehingga dapat mempertahankan postur tulang punggung yang fi siologis, dengan demikian diharapkan kerja otot tidak perlu berkontraksi secara berlebihan (Meily, 2013).

\section{PEMBAHASAN}

Menurut Suma'mur (2014), keselamatan kerja adalah keselamatan yang bertalian dengan mesin, pesawat, alat kerja, bahan dan proses pengolahannya, landasan tempat kerja dan lingkungannya serta caracara melakukan pekerjaan. Salah satu tujuan K3 adalah untuk mencapai Zero Accident. (Ramli. 2010). Manajemen Risiko K3 adalah suatu upaya mengelola risiko untuk mencegah terjadinya kecelakaan yang tidak diinginkan secara komprehensif, terencana dan terstruktur dalam suatu kesisteman yang baik. Sehingga memungkinkan manajemen untuk meningkatkan hasil dengan cara mengidentifikasi dan menganalisis risiko yang ada (Soputan et, al, 2014). Manajemen risiko K3 berkaitan dengan bahaya dan risiko yang ada di tempat kerja yang dapat menimbulkan kerugian bagi peusahaan (Ramli, 2010).

HIRARC merupakan proses yang digunakan untuk mengidentifikasi dan mengevaluasi potensi bahaya pada tempat kerja dan metode yang digunakan untuk mengurangi atau menghilangkan bahaya yang teridentifikasi. Program pengendalian bahaya (Achmad, et,al, 2016). Implementasi K3 dimulai dengan perencanaan yang baik diataranya, identifikasi bahaya, penilaian dan pengendalian risiko yang merupakan bagian dari manajemen risiko. HIRARC inilah yang menentukan arah penerapan K3 dalam perusahaan. Berikut ini merupakan langkah-langkah manajemen resiko dengan menggunakan HIRARC:

\section{Hazard Identification}

2. Risk Assesment

3. Risk Control 


\section{MEMPERTAHANKAN ERGONOMIK PADA POSISI DUDUK}

Dimensi meja dan kursi belajar yang sesuai dengan dimensi tulang akan membuat jaringan otot bekerja dengan beban yang ringan. Jika meja dan kursi yang dirancang tidak ergonomis artinya jaringan otot di sekitarnya dipaksakan bekerja melebihi batas regangnya (untuk kegiatan menulis dan membaca). Kegiatan ini dilakukan secara berulang-ulang (repetitive), sehingga jaringan otot akan mengalami cedera (injury). Jika cedera ini dibiarkan terusmenerus akan gejala kelumpuhan jaringan otot, dan kondisi ini sungguh sangat tidak menguntungkan (Santoso, 2012).

Kursi untuk kerja dengan posisi duduk dirancang dengan metode floor-up, yaitu dengan berawal pada permukaan lantai, untuk menghindarkan adanya tekanan di bawah paha. Setelah ketinggian kursi didapat kemudian barulah menentukan ketinggian meja kerja yang sesuai dan konsisten dengan ruang yang diperlukan untuk paha dan lutut. Menurut Meily (2013), posisi duduk yang ergonomis di mana seseorang mempertahankan postur badan yang stabil dan memenuhi hal-hal sebagai berikut:

1. Menyenangkan dalam jangka waktu tertentu,
2. Memuaskan secara fisiologi, dengan duduk kita jadi lebih nyaman,

3. Sesuai/serasi/cocok dengan pekerjaan yang dilakukan

Lebih lanjut Meily (2013), mengemukakan prinsip duduk normal/santai adalah sebagai berikut:

1. Lutut fleksi 90 derajat.

2. Tubuh fleksi di atas pada 90 derajat.

3. Pelvis rotasi ke belakang 30 derajat atau lebih.

4. Berat badan bertumpu pada ischial tuberositas

5. Bagian atas tulang sacrum agak horizontal

Untuk mengurangi tekanan yang berlebihan pada tulang belakang dibutuhkan bantalan atau sandaran pada saat duduk. Desain sandaran duduk yang direkomendasikan adalah yang diberi lapisan busa untuk tujuan memberikan kenyamanan pada saat melakukan aktivitas sambil duduk untuk jangka waktu relative lama (selama kurang lebih 4 jam sebelum istirahat).

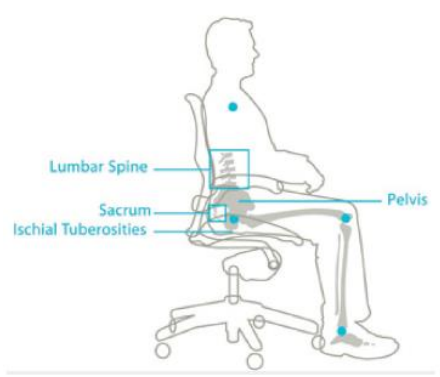


UPAYA PENCEGAHAN HAZARD PSIKOSOSIAL

Bahaya Psikososial merupakan bahaya pekerjaan yang memengaruhi kesejahteraan psikologis pekerja termasuk kemampuan untuk berpartisipasi dalam lingkungan kerja diantara orang lain. Berdasarkan identifikasi bahaya yang dilakukan pada rumah sakit ditemukan bahwa terdapat beberapa keluhan klien dengan masalah kualitas pelayanan penanganan pasien yang dapat memengaruhi citra Rumah Sakit Hewan Prof. Soeparwi. Keluhan yang terjadi disebabkan ketidakpuasan hasil kerja petugas, tekanan dari pemilik hewan yang meminta ganti rugi saat pasien terlepas dan kabur sehingga memengaruhi hubungan antara klien dan pihak rumah sakit, kemudian terdapat komplain klien terhadap hasil unit kerja bagian grooming sehingga memengaruhi kepuasan klien dengan kinerja petugas sehingga dapat berdampak pada stress kerja. Petugas kesehatan mengalami kelelahan emosional yang berdampak padas stress kerja dan mungkin berdampak lebih sehingga dapat mengalami burnout.

Lingkungan dan kondisi kerja yang tidak sehat merupakan beban tambahan kerja bagi karyawan atau tenaga kerja (Notoatmodjo, 2003). Dalam melaksanakan pekerjaannya seseorang akan membangun lingkungan kerja yang nyaman dan juga menggunakan tekologi untuk membantunya bekerja agar lebih efektif, efisien dan produktif (Ndraha, 2005).

Lingkungan kerja yang nyaman dan manusiawi merupakan faktor pendorong semangat dan efisiensi kerja karyawan. Bila lingkungan kerja buruk akan menimbulkan penyakit akibat kerja Kondisi kerja tertentu dapat menghasilkan prestasi kerja yang optimal. Di samping dampaknya terhadap prestasi kerja, kondisi kerja fisik memiliki dampak terhadap kesehatan mental dan keselamatan kerja seorang tenaga kerja (Munandar, 1995). Menurut Saydam (2000) lingkungan kerja sebagai keseluruhan sarana prasarana kerja yang ada disekitar karyawan yang sedang melaksanakan pekerjaan yang dapat mempengaruhi pekerjaan itu sendiri. Lingkungan kerja didesain sedemikian rupa agar dapat tercipta hubungan kerja yang mengikat pekerja dengan lingkungan (Lewa, 2005).

Bahaya Psiko-sosial, yaitu potensi bahaya yang berasal atau ditimbulkan oleh kondisi aspek-aspek psikologis ketenagakerjaan yang kurang baik atau kurang mendapatkan perhatian seperti :

- Penempatan tenaga kerja yang tidak sesuai dengan bakat, minat, kepribadian, motivasi, temperamen atau pendidikannya. 
- Sistem seleksi dan klasifikasi tenaga kerja yang tidak sesuai

- Kurangnya keterampilan tenaga kerja dalam melakukan pekerjaannya sebagai akibat kurangnya latihan kerja yang diperoleh

- Hubungan antara individu yang tidak harmoni dan tidak serasi dalam organisasi kerja.

Upaya yang dilakukan untuk mencegah hazard psikososial yakni:

1. Analisis Beban Kerja untuk menetapkan jumlah jam kerja orang yang digunakan atau dibutuhkan untuk merampungkan suatu pekerjaan dalam waktu tertentu, atau dengan kata lain analisis beban kerja bertujuan untuk berapa jumlah personalia dan tanggung jawab yang dilimpahkan kepada seorang petugas.

2. Memberikan kesempatan dalam pengembangan saat kerja, pengembangan karir merupakan suatu perencanaan dan penerapan rencana karir yang dapat digunakan untuk penempatan perawat pada jenjang yang sesuai dengan keahliannya
3. Penentuan/Penyesuaian desain kerja, desain pekerjaan adalah rincian tugas dan cara pelaksanaan tugas atau kegiatan yang mencakup siapa yang mengerjakan tugas, bagaimana tugas itu dilaksanakan, dimana tugas dikerjakan dan hasil apa yang diharapkan.

\section{PENUTUP}

Dalam melaksanakan pekerjaannya seseorang akan membangun lingkungan kerja yang nyaman dan juga menggunakan tekologi untuk membantunya bekerja agar lebih efektif, efisien dan produktif (Ndraha, 2005).

Besar kecil nya suatu kecelakaan akan berdampak besar pada suatu perusahaan dan pada karyawan yang bekerja pada perusahaan itu sendiri.

Dalam ergonomi, postur tubuh adalah faktor yang sangat penting, salah satunya postur duduk yang setiap orang lakukan setiap hari dalam durasi berjamjam. Tujuan utama membuat desain ergonomi untuk kursi atau tempat duduk dan meja adalah menciptakan sedemikian rupa bentuk kursi dan meja belajar, sehingga dapat mempertahankan postur tulang punggung yang fisiologis, dengan demikian diharapkan kerja otot tidak perlu berkontraksi secara berlebihan (Meily, 2013). 


\section{DAFTAR PUSTKA}

Daniah. Fauzi, Rizki Zulfikri. (2016). HUBUNGAN GEJALA STRES KERJA DENGAN BAHAYA PSIKOSOSIAL PADA PEKERJA PENGUMPUL TOL CABANG JAGORAWI DI PT. JASA MARGA (PERSERO) TBK TAHUN 2016. Jurnal Ilmu Kesehatan, 8(2); 25-29.

Fathi, A., \& Simamora, R. H. (2019, March). Investigating nurses' coping strategies in their workplace as an indicator of quality of nurses' life in Indonesia: a preliminary study. In IOP conference series: Earth and Environmental science (Vol. 248, No. 1, p. 012031). IOP Publishing.

Kemala, Aliva. (2018). FAKTOR PSIKOSOSIAL LINGKUNGAN KERJA (STUDI KASUS) PADA KARYAWAN PABRIK SSP PT. X. Jurnal Psikologi Volume 11 No.1, 95-106.

Kurniawa, Bambang Kartono. Fajarwati, Ade. Nangnoy, Oktavianus. (2018). PENERAPAN ERGONOMI DALAM PERANCANGAN FURNITUR MATA KULIAH DF IV DESAIN INTERIOR DI UNIVERSITAS BINA NUSANTARA JAKARTA. Jurnal ATRAT V6/N1/01, $42-48$.

Mantiri, E. Z. R. A,. Pinontoan, Odi R,. Mandey, Sylvia. (2020). FAKTOR PSIKOLOGI DAN PERILAKU DENGAN PENERAPAN MANAJEMEN KESELAMATAN DAN KESEHATAN KERJA RUMAH SAKIT. Indonesian Journal of Public Health and Community Medicine Vol. 1, No. 3, 19-27.

Nilamsari, Neffrety. Soebinjato. dkk. (2015). PROTOTYPE BANGKU ERGONOMIS UNTUK MEMPERBAIKI POSISI DUDUK SISWA SMAN DI KABUPATEN GRESIK. Jurnal Ners Vol. 10 No. 1: 87-103.

Ramdan, Iwan M. Rahman, Abd. (2017). Analisis Risiko Kesehatan dan Keselamatan Kerja (K3) pada Perawat. JKP - Volume 5 Nomor 3, 229-241.

Salawati, Liza. (2015). PENYAKIT AKIBAT KERJA DAN PENCEGAHAN. JURNAL KEDOKTERAN SYIAH KUALA Volume 15 Nomor 2, 91-95.

Simamora, R. H. (2020). Learning of Patient Identification in Patient Safety Programs Through Clinical Preceptor Models. Medico Legal Update, 20(3), 553-556.

Suartini, Luh Putu. (2015). RISIKO ERGONOMI PENYAKIT AKIBAT KERJA PADA PERAWAT GIGI. Jurnal Kesehatan Gigi Vol. 3 No. 2, 113-123. 
Supriyadi. Ramdan, Fauzi. (2017). IDENTIFIKASI BAHAYA DAN PENILAIAN RISIKO PADA DIVISI BOILER MENGGUNAKAN METODE HAZARD IDENTIFICATION RISK ASSESSMENT AND RISK CONTROL (HIRARC). Journal of Industrial Hygiene and Occupational Health Vol. 1, No. 2. 